\title{
Knowledge, attitudes and metabolic control of diabetic and cardiac patients
}

\author{
Conhecimento, atitudes e controle metabólico de diabéticos cardiopatas
}

Bruna Emy Ono ${ }^{1}$, Carolina Rodrigues Mendes Nogueira Cobra ${ }^{1}$, Claudia Castelo Branco de Castro ${ }^{1}$, Elisabete Sabetta Margarido ${ }^{1}$, Rita de Cassia Gengo e Silva ${ }^{1}$

Objective: to verify the relationship between knowledge, attitudes and metabolic control in diabetic and cardiac patients. Methods: descriptive, exploratory and cross-sectional study exploring the knowledge, attitudes and diabetes metabolic control in 46 participants with heart disease. Results: participants were predominantly male with incomplete secondary education who demonstrated poor knowledge and unfavorable attitudes towards the disease. There was no difference between participants with and without knowledge on variables of metabolic and clinical control of diabetes, neither with respect to attitudes towards the disease. Conclusion: knowledge about diabetes was unsatisfactory in patients with heart disease and unrelated to favorable actions and better disease control.

Descriptors: Knowledge; Diabetes Mellitus; Heart Diseases; Education.

Objetivo: verificar a relação do conhecimento, atitudes e controle metabólico de diabéticos cardiopatas. Métodos: estudo descritivo, exploratório e transversal que verificou conhecimento, atitudes e controle metabólico do diabetes em 46 participantes com cardiopatia. Resultados: os participantes eram predominantemente do sexo masculino, com ensino médio incompleto, que demonstraram conhecimento insatisfatório e atitudes desfavoráveis em relação à doença. Não houve diferença entre os participantes com e sem conhecimento em relação às variáveis de controle metabólico e clínico do diabetes, tampouco com atitudes frente à doença. Conclusão: o conhecimento sobre diabetes mostrou-se insatisfatório em pacientes com cardiopatia e não se relacionou a atitudes favoráveis e melhor controle da doença.

Descritores: Conhecimento; Diabetes Mellitus; Cardiopatias; Educação.

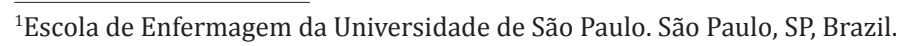




\section{Introduction}

Cardiovascular diseases rank first among the causes of death in Brazil and in developed countries ${ }^{(1)}$. Its genesis is attributed to multiple risk factors, among which stands out diabetes ${ }^{(2)}$.

Diabetes mellitus type 2 is a chronic disease characterized as metabolic disorder of multiple etiology, resulting from defects in insulin production, secretion or action, and associated with chronic hyperglycemia and disorders in the metabolism of carbohydrates, lipids and proteins ${ }^{(3)}$.

Control of the disease depends on the appropriate treatment, which includes the use of drugs and changes in lifestyle. Such changes require the acquisition of knowledge about the disease and its consequences as well as the treatment and recognition of signs and symptoms of decompensation. In Brazil, a cross-sectional study in a Basic Health Unit in the State of São Paulo showed that research participants had unsatisfactory level of knowledge ${ }^{(4)}$. Other authors have found that personal and cultural factors hinder the adoption of self-care actions to prevent diabetesrelated problems ${ }^{(5)}$.

In fact, the need for lifestyle changes requires coping skills for the adjustments that are necessary to maintain health and control the diabetes mellitus type 2 . The commitment to adhere or the desire to quit treatment, translated into positive or negative attitude towards the disease, respectively, is present in the person's daily life with the disease ${ }^{(6)}$.

Iranian researchers evaluated 200 patients with diabetes type 2 and found that $61.4 \%$ of them had satisfactory level of knowledge, 50.4\% had favorable attitudes and $52.2 \%$ had favorable practices. They observed that age, duration of disease and presence of complications (retinopathy) were significantly correlated with knowledge, attitudes and practices related to diabetes mellitus type $2^{(7)}$.

Another study with 405 patients in primary care showed that patients with more knowledge and strong beliefs about the need to use anti-diabetic drugs were more likely to adhere to treatment ${ }^{(8)}$.

Investigating the knowledge and attitudes of diabetic patients facing the disease is important because strategies to increase the knowledge about the disease, as well as the modification of beliefs and behaviors contributes to positive outcomes in the health of these people, such as better glycemic control.

The aim of this study was to verify the relationship between knowledge, attitudes and metabolic control in diabetic and cardiac patients.

\section{Methods}

Descriptive, exploratory and cross-sectional study, conducted in June-November 2015, in the outpatient facility of a large hospital specialized in cardiology in São Paulo, Brazil.

The study target population consisted in cardiac patients with diabetes mellitus type 2, under outpatient care, and referred to participate in the Diabetes Group of the abovementioned service. Such patients are identified during medical consultations as new cases of diabetes, non-adherent to treatment or with inadequate control of diabetes, based on laboratory test results.

The sample chosen by convenience consisted in 46 participants who met the following inclusion criteria: patients with age $>18$ years, of both sexes; with established medical diagnosis of diabetes mellitus type 2; invited to attend the Diabetes Group; and willing to participate in the study. Patients diagnosed with diabetes type 1, gestational diabetes, glucose intolerance, or unable to answer the questionnaire were excluded.

To identify eligible participants, one of the researchers had access to the monthly schedule of patients invited to join the group. With the list in hands, all patients scheduled were contacted through a telephone call to explain the objectives and purposes of the study and to request the attendance of those who showed willingness to participate in the research one hour before starting activities in the Diabetes Group. 
On the scheduled day, participants were approached in an appropriate place. The researcher explained again the research objectives and how the collection of data would be carried out.

During the data collection period, 360 patients were invited to participate in the diabetes group; 216 patients attended the group, and 162 of these were patients with diabetes mellitus type 2.0n the meeting of the Diabetes Group, they were informed about the objectives and form of participation in the study. There was refusal in the case of 116 patients. The reasons were: the participation in the study would not bring them direct benefits; time spent on the way between home and the hospital; and need to leave work earlier. Therefore, 46 patients agreed to participate and signed the informed consent.

Data collection was performed before the patient's participation in the Diabetes Group. Participants filled an instrument containing sociodemographic information, the Diabetes Knowledge Scale (DKN-A) and the Questionnaire of Psychological Attitudes of Diabetes (ATT-19). Clinical and metabolic variables were collected through research in medical records and, for this study, the records immediately performed before participating in the Diabetes Group were considered.

The Diabetes Knowledge Scale (DKN-A) is a self-applied questionnaire containing 15 items with multiple choice answers on various aspects related to general knowledge on diabetes. It presents five broad categories: basic physiology - including the action of insulin, hypoglycemia, food groups and their replacements, diabetes management and its complications and general principles of care ${ }^{(4,9)}$.

Each item is assigned a point if correctly answered and zero if incorrectly answered. Items 1 to 12 require a single correct answer. For items 13 to 15 , there is more than one correct answer and all should be checked for the answer be considered correct. The total score of the instrument is the sum of the points assigned to each item and this can vary from 0 to $15^{(4,9)}$. Scores greater than eight indicate good knowledge about diabetes. This cutoff value was used to divide the sample into two groups: with and without knowledge on diabetes mellitus.

Psychological Attitudes of Diabetes (ATT 19) is a self-applied questionnaire on a measure of psychological adjustment for diabetes, developed in response to the need to assess psychological and emotional aspects about the disease. The questionnaire consists of 19 items that include six factors: stress associated with diabetes, amenability to treatment, confidence in the treatment, personal effectiveness, perception of health and social acceptance. Questions 11, 15 and 18 have reverse score. Each response is measured in a Likert type scale with five points (from strongly disagree to strongly agree). The total score ranges from 19 to 95 points. Scores above 70 points indicate a positive attitude towards the disease ${ }^{(4,9)}$.

Data were entered into an electronic spreadsheet and analyzed using descriptive and inferential statistics. The Student $t$-test was used for comparing means of two groups. When the assumption of normality was not met, we used the Mann-Whitney test. To test the homogeneity between proportions, the chi-square test or Fisher's exact test were used. The significance level used for the tests was 5.0\%.

The study complied with the formal requirements contained in the national and international regulatory standards for research involving human beings.

\section{Results}

The average age of participants was 63.2 years $(\mathrm{SD}=8.31)$ and the majority were male $(\mathrm{n}=25$; $54.4 \%)$.Regarding the level of education, 22 (47.8\%) had complete primary education and 17 (37.0\%) had completed high school.

The time from diagnosis of diabetes type 2 
ranged from 1 to 420 months (median of 72 months), with a mean of 95.4 months (SD=84.9). Further clinical data are shown in Table 1.

Table1 - Clinical Characteristics and metabolic control of diabetes of the study participants $(n=46)$

\begin{tabular}{|c|c|c|c|c|c|}
\hline Variable & Mean & $\begin{array}{l}\text { Standard } \\
\text { deviation }\end{array}$ & Median & $\begin{array}{l}\text { Mini- } \\
\text { mum }\end{array}$ & $\begin{array}{l}\text { Maxi- } \\
\text { mum }\end{array}$ \\
\hline Body mass index $\left(\mathrm{kg} / \mathrm{m}^{2}\right)$ & 32.1 & 5.6 & 31.6 & 22.1 & 50.2 \\
\hline Abdominal circumference $(\mathrm{cm})$ & 108.3 & 13.7 & 106.0 & 84.0 & 145.0 \\
\hline \multicolumn{6}{|l|}{ Laboratory tests } \\
\hline Triglycerides $(\mathrm{mg} / \mathrm{dL}, \mathrm{n}=45)$ & 201.5 & 129.8 & 185.0 & 46.0 & 561.0 \\
\hline Total cholesterol(mg/dL, $\mathrm{n}=45)$ & 179.6 & 49.3 & 173.0 & 12.0 & 314.0 \\
\hline Glycemia (mg/dL, n = 45) & 175.1 & 71.1 & 147.0 & 95.0 & 419.0 \\
\hline $\begin{array}{l}\text { Low density lipoprotein (mg/ } \\
\mathrm{dL}, \mathrm{n}=44)\end{array}$ & 101.5 & 35.7 & 97.0 & 11.0 & 197.0 \\
\hline $\begin{array}{l}\text { High density lipoprotein (mg/ } \\
\mathrm{dL}, \mathrm{n}=45)\end{array}$ & 41.8 & 15.6 & 39.0 & 23.0 & 94.0 \\
\hline Glycated hemoglobin $(\% \mathrm{n}=35)$ & 7.8 & 1.9 & 7.5 & 5.0 & 11.3 \\
\hline \multicolumn{6}{|l|}{ Cardiovascular risk factors } \\
\hline High blood pressure & $44(95.7)$ & & & & \\
\hline Smoking & $3(6.5)$ & & & & \\
\hline Sedentary lifestyle & $37(80.4)$ & & & & \\
\hline Dyslipidemia & $39(84.8)$ & & & & \\
\hline $\begin{array}{l}\text { Family history of cardiovascular } \\
\text { disease }\end{array}$ & $18(39.1)$ & & & & \\
\hline
\end{tabular}

Participants were obese (Mean body mass in$\left.\operatorname{dex}=32.1 \pm 5.6 \mathrm{Kg} / \mathrm{m}^{2}\right)$, had accumulation of abdominal fat (waist circumference $=108.3 \pm 13.7 \mathrm{~cm}$ ) and had inadequate glycemic control (Glycated hemoglobin $=7.8 \pm 1.9 \%$ ). Most participants had other cardiovascular risk factors in addition to diabetes type 2, such as hypertension and dyslipidemia. Smoking was documented for only $6.5 \%$ of participants.

With regard to drug therapy, it was observed that $45(97.8 \%)$ participants had prescription of drugs acting on the cardiovascular system, 39 (84.8\%) of antilipemics, $35(76.1 \%)$ of oral hypoglycemic agents, $31(67.4 \%)$ of anticoagulants, $10(21.7 \%)$ of antiplatelets, and 10 (21.7\%) of insulin; 21 (45.7\%) participants had prescription of drugs from other classes, such as anxiolytics and benzodiazepines.

Among the 46 participants, 27 (58.7\%) were classified as not having knowledge on diabetes mellitus. Only two (4.3\%) participants showed a positive attitude towards the disease. Table 2 shows the descriptive statistics of scores obtained in the assessments of knowledge and attitude.

Table 2 - Descriptive values of knowledge and attitude scores of the study participants $(n=46)$

\begin{tabular}{lccccc}
\hline Variable & Mean & $\begin{array}{c}\text { Standard } \\
\text { Deviation }\end{array}$ & Median & $\begin{array}{c}\text { Mini- } \\
\text { mum }\end{array}$ & $\begin{array}{c}\text { Maxi- } \\
\text { mum }\end{array}$ \\
\hline DKN-A & 6.9 & 3.0 & 7.0 & 1.0 & 13.0 \\
$\begin{array}{l}\text { Psychological Attitu- } \\
\text { des of Diabetes }\end{array}$ & 53.1 & 9.5 & 53.0 & 36.0 & 71.0 \\
$\begin{array}{l}\text { DKN-A = Diabetes KnowledgeScale } \\
\text { DKNoter }\end{array}$ & & & & &
\end{tabular}

Participants were divided into two groups according to the score obtained in the DKN-A: the group with knowledge $(\mathrm{n}=19)$ and without knowledge $(\mathrm{n}=27)$. Participants in both groups had similar mean age $(61.0 \pm 8.5$ vs $64.8 \pm 7.9$ years, respectively, $\mathrm{p}=0.126)$. Distribution of participants according to sex $(\mathrm{p}=0.845)$ and education level was similar between the groups with and without knowledge $(\mathrm{p}=0.123)$. Table 3 shows the results of the relationship between knowledge on diabetes and the attitude towards the disease and variables related to clinical and metabolic control of the disease.

The groups with and without knowledge on diabetes did not show statistically significant differences with regard to the variables of clinical and metabolic control, neither with respect to scores on attitudes towards the disease. 
Table 3 - Comparison of participants with and without knowledge on diabetes according to the scores of attitudes and variables related to clinical and metabolic control of the disease $(n=46)$

\begin{tabular}{|c|c|c|c|c|c|c|c|}
\hline \multirow{3}{*}{ Variable } & \multicolumn{6}{|c|}{ Knowledge } & \multirow[b]{3}{*}{ p-value } \\
\hline & \multicolumn{3}{|c|}{ Yes $(\mathrm{N}=19)$} & \multicolumn{3}{|c|}{ No $(n=27)$} & \\
\hline & Mean & $\begin{array}{l}\text { Standard } \\
\text { deviation }\end{array}$ & n (\%) & Mean & $\begin{array}{l}\text { Standard } \\
\text { deviation }\end{array}$ & n (\%) & \\
\hline Body mass index $\left(\mathrm{kg} / \mathrm{m}^{2}\right)$ & 31.8 & 4.3 & - & 32.3 & 6.4 & - & $0.756^{(1)}$ \\
\hline Abdominal circumference $(\mathrm{cm})$ & 108.7 & 12.2 & - & 108.0 & 14.9 & - & $0.862^{(1)}$ \\
\hline Time since diagnosis of Diabetes Mellitus type 2 (months) & 95.2 & 81.5 & - & 95.6 & 88.9 & - & $0.864^{(1)}$ \\
\hline Glycated hemoglobin (\%) & 8.3 & 2.1 & - & 7.5 & 1.7 & - & $0.252^{(1)}$ \\
\hline Glycemia (mg/dL) & 175.8 & 66.3 & - & 174.6 & 75.7 & - & $0.955^{(1)}$ \\
\hline Triglycerides (mg/dL) & 200.3 & 126.7 & - & 202.4 & 134.5 & - & $0.957^{(1)}$ \\
\hline Total Cholesterol (mg/dL) & 172.1 & 50.7 & - & 185.1 & 48.5 & - & $0.386^{(1)}$ \\
\hline Low density lipoprotein (mg/dL) & 101.2 & 23.6 & - & 101.8 & 43.2 & - & $0.955^{(1)}$ \\
\hline High density lipoprotein (mg/dL) & 40.7 & 15.7 & - & 42.6 & 15.8 & - & $0.698^{(1)}$ \\
\hline High blood pressure & - & - & $17(89.5)$ & - & - & $27(100.0)$ & $0.165^{(2)}$ \\
\hline Smoking & - & - & $1(5.3)$ & - & - & $2(7.4)$ & $1.000^{(2)}$ \\
\hline Sedentary lifestyle & - & - & $17(89.5)$ & - & - & $20(74.1)$ & $0.270^{(2)}$ \\
\hline Dyslipidemia & - & - & $16(84.2)$ & - & - & $23(85.2)$ & $1.000^{(2)}$ \\
\hline Scores on Psychological Attitudes of Diabetes & 51.1 & 9.3 & - & 54.4 & 9.6 & - & $0.280^{(3)}$ \\
\hline
\end{tabular}

\section{Discussion}

Diabetes Mellitus is one of the five most relevant chronic diseases, whether by its increasing spread or by its complications ${ }^{(2)}$. Data from the Framingham Study show diabetes is also associated with increased cardiovascular risk ${ }^{(10)}$.

Among the evaluated participants, 27 (58.7\%) had poor knowledge, that is, obtained a score below eight in the DKN-A assessment. Similar results have been found in national and international studies ${ }^{(5,8)}$. The evaluation of the knowledge of Brazilian users of primary care with diagnosis of diabetes showed that $66.6 \%$ had poor knowledge ${ }^{(5-6)}$. In the present study, there was no relationship between knowledge about diabetes and the other variables analyzed.

Participants with and without knowledge had more than 60 years. Although the groups with and without knowledge presented similar mean age, the influence of age on knowledge about diabetes cannot be rejected. Researchers have found that age is a predictor of knowledge about the disease in Chinese elderly patients with diabetes mellitus type $2^{(11)}$. In another study, advanced age was associated with poor knowledge $(\mathrm{p}<0.001)^{(6)}$.

Participants of this study were mostly male. In contrast, researchers observed prevalence of diabetic females in southeastern Brazil(4). Another study, however, confirms the greater prevalence of diabetes among men ${ }^{(12)}$. Despite this, there seems to be no relationship between sex and knowledge about the disease $^{(12)}$.

One aspect that must also be considered in the present study is that participants had associated heart disease. US statistics show that, in the period 1997-2005, the prevalence of cardiovascular diseases adjusted for age in diabetic people was higher among men. During this period, there was a reduction 
of $11.2 \%$ in the prevalence adjusted for age of cardiovascular diseases among diabetic women, while the same was not true for men ${ }^{(13)}$.

The level of education was similar among participants with and without knowledge. However, lower levels of education are associated with less knowledge about the disease. Study that analyzed the factors associated with knowledge, attitudes and practices of diabetic patients showed that the chance of having enough knowledge about the disease was 17 times higher among those who had higher education compared to patients without education ${ }^{(14)}$. Knowledge about diabetes was significantly lower among participants who had completed high school compared to those who had more than 14 years of study ${ }^{(12)}$.

The mean time elapsed since diagnosis in this study was approximately eight years. No association was observed between the time of diagnosis and the knowledge about the disease. The literature is controversial in this regard ${ }^{(6-7)}$. The influence of the time since diagnosis over the knowledge about diabetes and the intervening variables in this relationship needs to be further explored.

The data on body mass index and waist circumference show that study participants were overweight and/or obese, and had abdominal fat accumulation. Altered weight and abdominal fat are well established risk factors for cardiovascular events $^{(2)}$. Moreover, it is shown that obesity adversely affects glycemic control ${ }^{(15)}$.

When it comes to relating knowledge about diabetes and the proper control of Glycated hemoglobin or fasting glucose, studies are contradictory. Jordanians researchers found a strong relationship between knowledge about diabetes and improvement in Glycated hemoglobin and fasting glucose ${ }^{(16)}$. In contrast, a study conducted in Saudi Arabia showed no relationship between knowledge and adequate control of glycosylated hemoglobin levels ${ }^{(17)}$.

The results related to risk factors for diabetes mellitus were similar to those obtained in another study in which no relationship between knowledge and risk factors was found, and that diabetes control does not depend on the presence of risk factors such as smoking, family history of diabetes mellitus or hypertension $^{(18)}$.

It was found that most participants had unfavorable attitude towards the disease and, therefore, unadjusted coping. Brazilian authors found variation of scores (35-80 points) similar to those observed in the present study when evaluating the attitudes of diabetic patients in primary care ${ }^{(4)}$. In another Brazilian study, it was observed that $97.6 \%$ of the individuals had scores lower than 70 in the ATT$19^{(6)}$. In the international arena, evaluation of attitude towards diabetes through different questionnaires shows similar results, so that adverse attitudes can be seen in up to $72.0 \%$ of patients ${ }^{(4,19)}$. Together, these data suggest difficulty to face this chronic disease whose treatment require several adjustments in lifestyle. These results are worrisome because favorable attitudes may provide better results in relation to the management of the disease ${ }^{(19)}$.

Although association between knowledge and attitudes was not observed in this study, Australian authors have found that knowledge was predictor of favorable attitudes in a sample of 291 diabetic patients $^{(20)}$. On the other hand, it is necessary to consider that knowledge can be only one aspect that modulates the attitude towards the disease.

It is important that the factors contributing to the progress as well as those related to inhibitory attitudes be identified and support be offered to patients in order to strengthen the positive beliefs and change the ideas that prevent them from adopting a coping attitude towards the disease.

This study has limitations such as the crosssectional design and data collection in a single center, which may limit the potential for generalization of the results. We must also take all variables into account, except knowledge and attitudes were collected from 
medical records and may have been influenced by the inadequacy or lack of completeness of records.

However, the results can contribute to advances in medical practice, research and teaching. The analysis of individual items of the DKN-A and ATT19 can guide the proposition and the psychosocial interventions test, specially designed for this profile of patients. In fact, both satisfactory knowledge and favorable attitudes can influence the appropriate clinical and metabolic control, in order to slow the worsening of cardiovascular diseases by the diabetes.

\section{Conclusion}

The data show that, besides diabetes, the sample had other risk factors such as hypertension and inadequate clinical and metabolic control, as shown by the values of laboratory tests and anthropometric measurements. The results suggest that the participants had insufficient knowledge on diabetes and adverse attitudes towards the disease. Moreover, there was no relationship between knowledge about the disease, clinical or metabolic control of diabetes and attitudes towards the disease.

\section{Collaborations}

Ono BE and Silva RCG contributed to the conception, design, analysis, data interpretation and writing of the article. Cobra CRMN, Castro CCB and Margarido ES contributed to the analysis and interpretation of data and writing of the article. All authors contributed to the critical review and approval of the version to be published.

\section{References}

1. Martins LN, Souza LS, Silva CF, Machado RS, Silva CEF, Vilagra MM, et al. Prevalência dos fatores de risco cardiovascular em adultos admitidos na unidade de dor torácica em Vassouras, RJ. Rev Bras Cardiol. 2011; 24(5):299-307.
2. Mozaffarian D, Benjamin EJ, Go AS, Arnett DK, Blaha MJ, Cushman M, et al. Heart disease and stroke statistic - 2015 update: a report from the American Heart Association. Circulation [Internet]. 2015 [cited 2016 Mar. 13];131(4). Available from: https://www.ncbi.nlm.nih.gov/ pubmed/25520374

3. Ministério da Saúde (BR). Secretaria de Atenção à Saúde. Departamento de Atenção Básica. Estratégias para o cuidado da pessoa com doença crônica: diabetes mellitus. Brasília: Ministério da Saúde; 2013.

4. Oliveira KCS, Zanetti ML. Knowledge and attitudes of patients with diabetes mellitus in a primary health care system. Rev Esc Enferm USP. 2011; 45(4):862-8.

5. Moraes SA, Freitas ICM, Gimeno SGA, Mondini L. Prevalência de diabetes mellitus e identificação de fatores associados em adultos residentes em área urbana de Ribeirão Preto, São Paulo, Brasil, 2006: Projeto OBEDIARP. Cad Saúde Pública. 2010; 26(5):929-41.

6. Rodrigues FFL, Santos MA, Teixeira CRS, Gonela JT, Zanetti ML. Relationship between knowledge, attitude, education and duration of disease in individuals with diabetes mellitus. Acta Paul Enferm. 2012; 25(2):284-90.

7. Niroomand $M$, Ghasemi $S N$, Karimi-Sari $H$, Kazempour-Ardebili S, Amiri P, Khosavi MH. Diabetes knowledge, attitude and practice (KAP) study among Iranian in-patients with type2diabetes: a cross-sectional study. Diabetes Metab Syndr. 2016; 10(1 Suppl 1):114-9.

8. Sweileh WM, Zyoud SH, Nab'a RJA, Deleq MI, Enaia MI, Nassar SM, et al. Influence of patients' disease knowledge and beliefs about medicines on medication adherence: findings from a cross-sectional survey among patients with type 2 diabetes mellitus in Palestine. BMC Public Health [Internet]. 2014 [cited 2016 Mar. 13];14:94. Available from: http://bmcpublichealth.biomedcentral.com/ articles/10.1186/1471-2458-14-94

9. Torres HC, Hortale VA, Schall VT. Validação dos questionários de conhecimento (DKN-A) e atitude (ATT-19) de diabetes mellitus. Rev Saúde Pública. 2005; 39(6):906-11. 
10. Reynoso-Noverón N, Mehta R, Almeda-Valdes P, Rojas-Martinez R, Villalpando S, Hernández-Ávila $M$, et al. Estimated incidence of cardiovascular complications related to type 2 diabetes in Mexico using the UKPDS outcome model and a populationbased survey. Cardiovasc Diabetol [Internet]. 2011 [cited 2016 Mar. 13];10:1. Available from: https://www.ncbi.nlm.nih.gov/pmc/articles/ PMC3023678/

11. Hu J, Gruber KJ, Liu H, Zhao H, Garcia AA. Diabetes knowledge among older adults with diabetes in Beijing, China. J Clin Nurs. 2013; 22(1-2):51-60.

12. Fenwick EK, Xie J, Rees G, Finger RP, Lamoureux EL. Factors associated with knowledge of diabetes in patients with type 2 diabetes using the diabetes knowledge test validated with Rasch analysis. Plos One [Internet]. 2013 [cited 2016 Mar. 13]; 8(12):e80593. Available from: https://www.ncbi. nlm.nih.gov/pmc/articles/PMC3848993/

13. Centers for Disease Control and Prevention. National diabetes fact sheet: national estimates and general information on diabetes and prediabetes in the United States 2011, Atlanta, GA: U.S. Department of Health and Human Services, Centers for Disease Control and Prevention; 2011.

14. Gautam A, Bhatta DN, Aryal UR. Diabetes related health knowledge, attitude and practice among diabetic patients in Nepal. BMC Endocr Disord [Internet]. 2015 [cited 2016 Mar. 13];15:25. Available from: http://bmcendocrdisord. biomedcentral.com/articles/10.1186/s12902015-0021-6
15. Bae JP, Lage MJ, Mo D, Nelson DR, Hoogwerf BJ. Obesity and glycemic control in patients with diabetes mellitus: analysis of physician electronic health records in the US from 2009-2011. J Diabetes Complications. 2016; 30(2):212-20.

16. Hammad S, Darawad M, Hourani E, Demeh W. Predictors of glycated hemoglobin among Jordanian diabetic patients. Iran J Public Health. 2015; 44(11):1482-91.

17. Al-Maskari F, El-Sadig M, Al-Kaabi JM, Afandi B, Nagelkerke N, Yeatts KB. Knowledge, attitude and practices of diabetic patients in the United Arab Emirates. Plos One [Internet]. 2013 [cited 2016 Mar. 13]; 8(1):e52857. Available from: http:// journals.plos.org/plosone/article?id=10.1371/ journal.pone.0052857

18. Borg R, Vistisen D, Witte DR, Borch-Johnsen K. Comparing risk profiles of individuals diagnosed with diabetes by OGTT and Hb1Ac. The Danish inter99 study. Diabet Med. 2010; 27(8):906-10.

19. Oliveira KC, Zanetti ML. Knowledge and attitudes of patients with diabetes mellitus in a primary health care system. Rev Esc Enferm USP. 2011; 45(4):862-8.

20. Kueh YC, Morris T, Borkoles E, Shee H. Modelling of diabetes knowledge, attitudes, self-management, and quality of life: a cross-sectional study with an Australian sample. Health Qual Life Outcomes [Internet]. 2015 [cited 2016 Mar. 13];13:129. Available from: https://www.ncbi.nlm.nih.gov/ pubmed/26286395 